\title{
Pengolahan Limbah Baglog Jamur Tiram Menjadi Pupuk Organik Komersil
}

\author{
Hunaepi $^{1}$, Iwan Dodi Dharmawibawa ${ }^{1}$, Taufik Samsuri' ${ }^{1}$, Baiq Mirawati ${ }^{1}$, Muhammad Asy'ari ${ }^{2}$ \\ ${ }^{1}$ Program Studi Pendidikan Biologi, IKIP Mataram \\ ${ }^{2}$ Program Studi Pendidikan Olahraga IKIP Mataram, \\ Email korespondensi: hunaepi@ikipmataram.ac.id
}

\begin{abstract}
Abstrak
Dusun Bat Rurung desa Barejulat terdapat budidaya jamur tiram (Pleurotus osteatus) yang dikelola oleh kelompok budidaya jamur tiram Lombok. Kelompok ini disamping memproduksi jamur tiram juga memproduksi limbah berupa limbah baglog jamur tiram dalam jumlah satu kali masa panen kurang lebih $1 \mathrm{~s} / \mathrm{d} 2$ ton. Kondisi limbah yang sangat banyak mengakibatkan pencemaran pada lingkungan, ini dikarenakan anggota kelmpok pembudidaya tidak memiliki pengetahuan dan keterampilan dalam pengolahan limbah baglog media jamur tersebut. Baglog merupakan media tanam jamur tiram yang terbuat dari serbuk gergaji dan beberapa bahan nutrisi sebagai sumber nutrisi bagi pertumbuhan jamur. Limbah banglog jamur terbagi menjadi dua jenis yakni baglog kotaminan dan baglong tua. Kurangnya keterampilan pembudidaya dalam pengolahan limbah menjadi acuaan dasar untuk melakukan pelatihan pengolahan limbah baglog menjadi pupuk organik. Metode dan pendekatan yang digunakan dalam kegiatan ini dalam proses menyelesaikan perasalah yang ada adalah dengan diskusi dan praktek (learning by doing) gabungan kedua metode tersebut diharapkan mampu meningkatkan pemahaman dan keterampilan berkaitan dengan pengelolaan Limbah baglog media jamur tiram menjadi pupuk organik. Adapun hasil yang dicapai adalah 1) adanya pengetahuan dan keterampilan kelompok budidaya jamur tiram dalam mengolah limbah baglog menjadi pupuk organik, 2) meningkatnya partisifasi kelompok selama kegiatan pelatihan pengolahan hingga $85 \%$, 3) dihasilkannya produk berupa pupuk organik padat, dan 4) terbentuknya unit usaha tambahan yakni usaha pupuk organik.
\end{abstract}

Kata Kunci: Limbah Baglog, Jamr Tiram, Pupuk Organik

\begin{abstract}
Bat Rurung hamlet of Barejulat village is cultivated oyster mushroom (Pleurotus osteatus) which is manage by group of oyster mushroom cultivation of Lombok. This group in addition to producing oyster mushrooms also produce waste in the form of baglog oyster mushroom waste in the amount of one time of harvest of approximately $1 \mathrm{~s} / d 2 \mathrm{tons}$. The condition of waste is very much pollution cause in the environment, this is because members of the group of farmers do not have knowledge and skills in processing baglog mushroom waste. Baglog is an oyster mushroom planting media made from sawdust and some nutrients as a source of nutrients for the growth of fungi. Wastes mushroom banglog is divided into two types namely baglog contaminants and old baglong. The lack of cultivation skills in the processing of waste become the basic basis to conduct baglog waste processing training into organic fertilizer. The methods and approaches used in this activity in the process of solving the problems that exists is with the discussion and practice (learning by doing) the combination of both methods is expected to improve understanding and skills related to the management of baglog media of oyster mushrooms into organic fertilizer. The result is 1) the knowledge and skill of the oyster mushroom cultivation group in processing the baglog waste into organic fertilizer, 2) the increase of group participation during the processing training activities up to $85 \%$; 3) the result of the product in the form of solid organic fertilizer, and 4) the formation of unit Additional business is organic fertilizer business.
\end{abstract}

Keyword: Wastes Baglog, Oyster Mushroom, Organic Fertilizer 
Format Sitasi: Hunaepi, Dharmawibawa I.D., Samsuri, T., Mirawati, B., \& Asy'ari, M. (2018). Pengolahan

Limbah Baglog Jamur Tiram Menjadi Pupuk Organik Komersil. Jurnal SOLMA. 7(2), 277-288. Doi: http://dx.doi.org/10.29405/solma.v7i2.1392.

Diterima: 7 Juli 2018 | Revisi: 14 Agustus 2018 | Dipublikasikan: 30 Oktober 2018

\section{PENDAHULUAN}

Dusun Bat Rurung meruapkan salah satu dusun yang terletak di desa Barejulat, Kecamatan Jonggat, Kabupaten Lombok Tengah, terletak $11.3 \mathrm{~km}$ dari pusat Kota Praya dan sekitar $31 \mathrm{~km}$ dari kota Mataram. Jumlah sebaran penduduk di Dusun Bat Rurung laki-laki berjumlah 422 orang dan perempuan berjumlah 425 orang dengan total jumlah seberan 847orang. Tercatat bahwa data jumlah KK yang tergolong miskin berjumlah 100 Kepala Keluarga (KK) (Ardningsih, dkk., 2018). Sarana dan prasaran trasportasi telah tersedia dengan baik. Masyakarat banyak berkerja sebagai buruh tani, buruh bangunan, dan hanya beberapa yang bekerja sebagai PNS, dan TNI. Masyarakat Dusun Bat Rurung sebagian besar bekerja sebagai petani dengan penghasilan pas-pasan untuk memenuhi kebutuhan sehari-hari. Penghasilan yang hanya bersumber dari hasil pertanian menjadikan masyarakat dusun Bat Rurung tergolong masyarakat yang menengah kebawah.

Masyarakat dusun Bat Rurung selain sebagai petani, sebagian masyarakatnya ada yang membudidayakan jamur tiram yang tergabung dalam kelompok budidaya jamur tiram Lombok, kelompok ini mulai di rintis oleh Pak Sanapi pada tahun 2013 dengan 1 kumbung (rumah jamur) dengan kapasitas 1000 buah baglog, saat ini kelompok budidaya ini memiliki kumbung dengan kapasitas 4500 buah baglog, kelompok ini tidak hanya menjual jamur tiram akan tetapai juga menjual baglog jamur tiram yang telah disemaikan bibit jamur dengan pertumbuhan miselium $30 \%$ s/d 65\%. Jumlah produksi baglog dan jamur yang banyak diberengi dengan jumlah limbah baglog yang dihasilkan tercatat bahwa dalam satu kali siklus masa panen jamur dapat meghasilkan sekitar $1 \mathrm{~s} / \mathrm{d} 2$ ton limbah baglong jamur. Limbah baglog jamur merupakan media tanam jamur tiram yang telah habis masa penen, limbah yang dihasilkan berupa baglog tua dan baglog kontaminan. Dengan adanya jumlah limbah yang melimpah tanpa ada upaya pengolahan dari kelompok pembudidaya mengakibatkan adanya pencemaran udara, dan tanah disekitar pembuangan limbah tesebut.

Limbah baglog yang dihasilkan memiliki kandungan nutrisi yang dibutuhkan oleh tanaman, dan untuk perbaikan unsur hara tanah, konposisi limbah tersebut memiliki kandungan nutrisi seperti $\mathrm{P}$ 0,7\%, K),02\%, $\mathrm{N}$ total 0,6\% dan C-organik 49,00\% sehingga bermanfaat untuk meningkatkan kesuburan tanah (Sulaiman 2011), Adanya komposisi kandungan tersebut, limbah media jamur memiliki potensi untuk diolah kembali menjadi pupuk kopos organik. Farhana, 2013 
menyatakan memanfaatkan limbah media jamur tersebut yaitu dengan mengomposkannya dan dijadikan sebagai pupuk kompos organik yang dapat bermanfaat bagi tanah dan tanaman. Selain itu Peniwiratri dalam Rahmah, (2016) menyatakan salah satu alternatif pengolahan limbah yaitu dengan memanfaatkan limbah baglog menjadi pupuk organik melalui proses pengomposan, sedangkan Alex (2013) menyatakan kompos dapat polusi udara karena pembakaran limbah dan pelepasan gas metana dari sampah organik yang membusuk akibat bakteri metanogen ditempat pembuangan limbah, selain itu dapat memperbaiki struktur dan karakteristik tanah. Dengan pengolahan limbah menjadi pupuk dapat mengurangi pencemaran lingkungan yang ditimbulkan.

Limbah media jamur yang dihasilkan pada dasarnya merupakan kompos organik yang telah mengalami proses dekomposisi sehingga pengolahan limbah ini tidak membutuhkan waktu lama untuk diubah menjadi pupuk organik siap pakai. Umumnya proses pembuatan pupuk organik memerlukan 2 s/d 3 bulan (Indriani, (2012). Sedangkan pembuatan pupuk organik dengan bahan baku limbah jamur membutuhkan waktu lebih cepat yakni 1 bulan (Hunaepi, dkk 2014).

Berdasarkan uraian di atas, untuk mengatasi persoalan tersebut maka dirasakan sangat penting untuk dilakukan kegiatan pengabdian kepada masyarakat dengan tema "Pengolahan Limbah Baglog Jamur Tiram Menjadi Pupuk Organik Komersil di Dusun Bat Rurung Desa Bare Julat Kecamatan Jonggat Kabupaten Lombok Tengah”

\section{MASALAH}

Budiadaya jamur tiram di NTB saat ini makin berkembang hal tersebut dikarenakan jamur tiram memiliki nilai komersil yang cukup tinggi, selain itu pembudidayaan tidak menghabiskan modal besar. Jumlah pembudidaya yang terus meningkat tidak dibarengi dengan pemahaman dan keterampilan tentang pengolahan limbah yang dihasilkan yang berupa limbah baglog media jamur.

Sebagai salah satu contoh subyek yang digunakan dalam kegiatan PKM ini adalah kelompok budidaya jamur tiram lombok di dusun Bat Rurung desa Bare Julat kecamatan Jonggat Kabupaten Lombok Tengah, berdasarkan hasil obserpasi ditemukan beberapa masalah antara lain; 1) kurangnya pendampingan terkait peningkatan keterampilan pengolahan limbah, 2) Kurangnya pengetahuan dan keterampilan kelompok budidaya jamur tiram dalam pengolahan limbah baglog jamur tiram, 3) adanya pencemaran lingkungan akibat dari pembuangan limbah media jamur disekitar lokasi pembudidayaan, dan 4) menurunya hasil panen karena banyaknya jumlah baglog yang terkontaminan disebabkan pembuangan limbah yang sebarangan. 


\section{METODE PELAKSANAAN}

Kegiatan ini dilaksanakan selama empat bulan yaitu dari buan maret sampai dengan juni 2018. Pengabdian ini dilaksanakan di Dusun Bat Rurung Desa Bare Julat, Kecamatan Jonggat Kabupaten Lombok Tengah. Kegiatan ini akan dilaksanakan pada kelompok budidaya jamur tiram Lombok yang beranggotakan 8 (delapan) orang yang terdri dari 5 (lima) orang laki-laki dan 3 (tiga) orang perempuan.

Adapun tahapan-tahan dalam kegaitan PKM pengolahan limbah media baglog jamur tiram ini adalah sebagai berkut;

1. Tahap Awal kegiatan

Tahap awal yang dilakukan dalam kegiatan ini adalah;

a. Menyiapkan materi tentang pembuatan pupuk kompos berbahan dasar limbah baglog jamur

b. Melakukan koordinasi dengan kepala desa Bare Julat dalam rangka koordinasi tentang kegiatan dan izin pelaksanaan kegiatan.

c. Melakukan koordinasi dengan kelompok budidaya jamur tiram Lombok dalam rangka pelaksanaan kegiatan dan melakukan cek ketersedian dan kelengkapan alat yang dibutuhkan untuk pembuatan pupuk kompos tersebut.

2. Tahap pelaksanaan kegiatan

Tahap pelaksanaan merupakan tahapan inti dari kegiatan PKM yang direncanakan, kegiatan inti tersebut antara lain;

a. Penyuluhan; kegiatan penyuluhan ini diisi dengan memberikan meteri tentang; 1) pentingnya berwirausaha dengan produk yang dikembangkan secara mandiri atau hand made, 2) teknik pembuatan pupuk orgnik berbahan dasar limbah baglog jamur tiram, 3) teknik pengemasan dan peluang usaha dari pupuk organik dengan melihat dan menganalisis PP (pinancial plant), BEP (Break Event Point), B/C (Benefit cost ratio), dan PP (Payback period).

b. Melakukan pendampingan dalam pembuatan pupuk organik berbahan dasar limbah baglog jamur tiram, yang dimulai dari kegiatan persiapan, pembuatan, dan pengemasan.

3. Tahap akhir kegiatan

Tahap akhir kegiatan PKM ini adalah; 
a. Melakukan evaluasi kualitas produk oleh tim PKM dan anggota kelompok dengan memperhatikan karateristik pupuk organik komersil

b. Melakukan evaluasi kualitas produk dilihat dari pengemasannya

c. Membuat kesepakaatan bersama bahwa produk yang dihasilkan siap dipasarkan

\section{HASIL DAN PEMBAHASAN}

Kegiatan ini dilakukan di lokasi pembudidayaan jamur tiram, dengan sasaran kelompok budidaya jamur tiram Lombok yang beranggotakan 8 orang. Kegiatan ini diakukan pada bulan Maret s/d Juli 2018. Pupuk organik saat ini menjadi salah satu alernatif terbaik sebagai pengganti kelangkaan dan mahalnya harga pupuk anorganik. Selain itu pupuk orgnik pada dasarnya memiliki manfaat yang sangat baik untuk pertumbuhan tanaman dan perbaikan struktur kandungan tanah. Adapun manfaatnya pupuk organik atau kompos secara umum adalah;

a. Mempertahankan dan meningkatkan kesuburan tanah

b. Memperbaiki struktur, tekstur aerasi dan drainase tanah

c. Meningkatkan kemampuan absorbsi panas dan menyerap air

d. Menggantikan unsur hara tanah yang hilang akibat terbawa oleh tanaman ketika dipanen atau terbawa aliran air permukaan (erosi)

Untuk mendapatkan manfaat di atas maka ada beberapa persyaratan yang harus dimiliki oleh pupuk organic atau kompos. Antara lain:

a. C-Organik minimal $15 \%$

b. $\mathrm{C} / \mathrm{N}$ rasio $15-25 \%$

c. Kadar air $15-25 \%$

d. $\mathrm{pH} 4-9$

e. Hara makro $\left(\mathrm{N}+\mathrm{P}_{2} \mathrm{O}_{5}+\mathrm{K}_{2} \mathrm{O}\right)$ minimal 4.

Membuat pupuk organik/kompos dengan menggunakan bahan dasar atau baha baku limbah baglog jamur dibutuhkan beberapa bahan dan alat antara lain limbah baglog jamur tiram $250 \mathrm{~kg}$, kotoran ternak (sapi) $100 \mathrm{~kg}$, EM4 $350 \mathrm{ml}$, gula $1 / 4 \mathrm{~kg}$, dedak $10 \mathrm{~kg}$, air Secukupnya, dan Azola pinata $3 \mathrm{~kg}$.

Cara pembuatan pupuk organik atau pupuk kompos limbah baglog jamur tiram digambarkan dalam bentuk diagram sebagai berikut: 


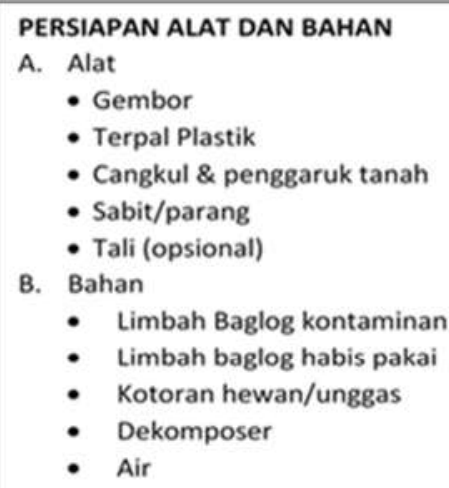

- Limbah Baglog kontaminan

- Limbah baglog habis pakai

- Kotoran hewan/unggas

- Dekomposer

- Air

Larutan 0.5 liter dekomposer EM4 ke dalam 20-25 liter

1. 0,5 liter dekomposer untuk $1 \times$ aplikasi ke 1 maupun pada proses penambahan dokomposer selanjutnya

2. Dosis dekomposer dapat berbeda sesuai produk yang digunakan

3. Konsentrasi larutan dekomposer dapat berubah sesuai kondisi bahan yang dikomposkan (jika kondisi bahan basah) maka air pelarut dekomposer dikurangi agar bahan kompos tidak terlalu basah \& lembab.

Bahan yang kering akan menghentikan aktivitas mikroba dan bahan yang terlalu basah akan mengganggu aerasi sehingga juga menghambat aktivitas penguraian oleh mikroba.
Siramkan larutan dekomposer dengan menggunakan gembor (secara merata dengan kondisi cukup basah) pada setiap lapisan kompos.

Note:

Kelembaban bahan kopos yang idela kurang lebih $30 \%$ (bila adonan dikapal dengan tangan, tidak ada air yang menetes dan bila kepalan dilepas adonan akan mekar)
Limbah baglog jamur kotaminan dan habis masa pakai

Pembuatan lubang/baik kompos (ukuran $1 \mathrm{~m} 3$ )

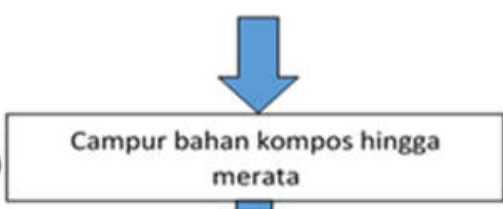

एक

Masukkan bahan kompos lapisan demi lapisan ke dalama lubang/baik Note:

- Tebal lapisan 10-15 cm

- Tutup dengan terpal एᄂ

Baik tumpukan kompos seminggu sekali

Note:

- Suhu pengomposan maximal $70^{\circ} \mathrm{C}$ (pembalikan dilakukan secara merata, diamkan selama lebih kurang 10 menit untuk menurunkan suhu, agar bakteri pengurai bekerja dengan optimal kembali)

- Siram dengan larutan dekomposer hingga kondisi cukup basah (kelembaban kurnag lebih 30\%)

- Tutup kembali dengan rapat setelah diaduk

Gambar 1. Skema Pembutan Pukuk Organik Padat Dari Limbah Baglog Jamur Tiram

\section{PELAKSANAAN KEGIATAN}

\section{Pelaksaan Koordinasi dengan Tim dan Pihak Mitra}

Pelaksanaan kegiatan diawali dengan koordinasi. Koordinasi tim pengabdian dengan kepala desa barejulat dan ketua kelompok budidaya jamur tiram Lombok pada kegiatan ini dibahasan tentang kegiatan yang akan dlaksanakan, lokasi/tempat dan waktu pelaksanaan penyuluhan dan pelatihan. Hasil dari kegiatan ini disepakati tentang kegiatan sosialisasi kegiatan, waktu pelaksanaan, tempat pelaksanaan, alat dan bahan yang dibutuhkan selama kegiatan, serta kebutuhan-kebutuhan pendukung lain yang dibutuhkan selama proses pelatihan pembuatan 
pengolahan limbah baglog jamur tiram menjadi pupuk oganik. Tanggapan dari kepala desa Bare julat dan ketua Kelompok Budidaya sangat positif dan disambut dengan baik.

\section{Pelaksanaan pembuatan pupuk}

1. Pemilihan bahan baku kompos

Pemilahan bahan baku dilakukan agar proses pengomposan lebih mudah dan cepat, selain itu proses ini dilakukan harus dengan teliti karena akan menentukan keberhasilan proses dan mutu kompos yang dihasilkan. Bahan-bahan anorganik seperti (karet, platik, kapas dan bahan berbahaya lainnya).

2. Penimbangan

Penimbangan dilakukan untuk menyesuaikan dengan standar formulasi yang ditentukan. Presentase penggunaan bahan tambahan disesuaikan dengan kebutuhan bahan baku limbah baglog jamur tiram agar dalam proses dekomposisi sesuai dengan apa yang diharapkan. Kegiatan penimbangan seperti yang terlihat pada gambar beriku ini.

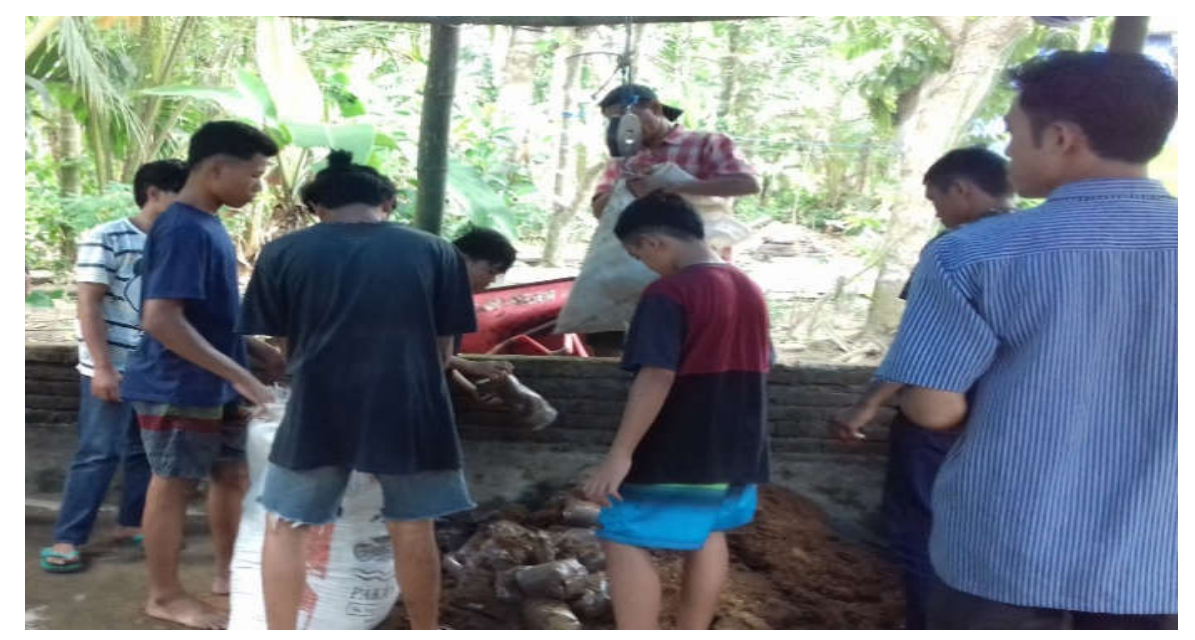

Gambar 2. Proses penimbangan bahan dasar pembuatan pupuk kompos (sumber: Doc. Pengambdian)

3. Pengecilan ukuran atau penghalusan bahan

Pengecilan ukuran bahan dilakukan untuk memperluas permukaan bahan baku, sehingga bahan baku dapat dengan mudah dan cepat didekomposisi menjadi kompos. Karena pada umumnya limbah baglog masih berupa bongkahan yang harus dihancurkan dihaluskan terlebih dulu. Peroses ini dilakukan dengan cara manual dengan menggunakan 
cangkul dan gareng. Setelah bahan-bahan hancur dilakukan pengayakan dengan menggunakan pengayak untuk mendapatkan bahan yang benar-benar bagus dan halus.

4. Pencampuran bahan kompos

Bahan baku kompos yang telah melewati tahap pemilahan dan penghalusan, kemudian melalui proses pencampuran. Semua bahan seperti: Baglog jamur yang telah disortir dari bahan anorganik, sisa jamur (jika ada), dedak, larutan gula aren, EM4 dan bahan tambahan seri Azolla pinnata, serta air dicampur merata. Takaran campuran bahan kompos mengikuti formula.

Kegiatan pencampuan bahan-bahan yang dikomposkan secara aktif dilakukan oleh semua anggota kelompok, hal tersebut dapat dilihat seperti pada gambar berikut ini;
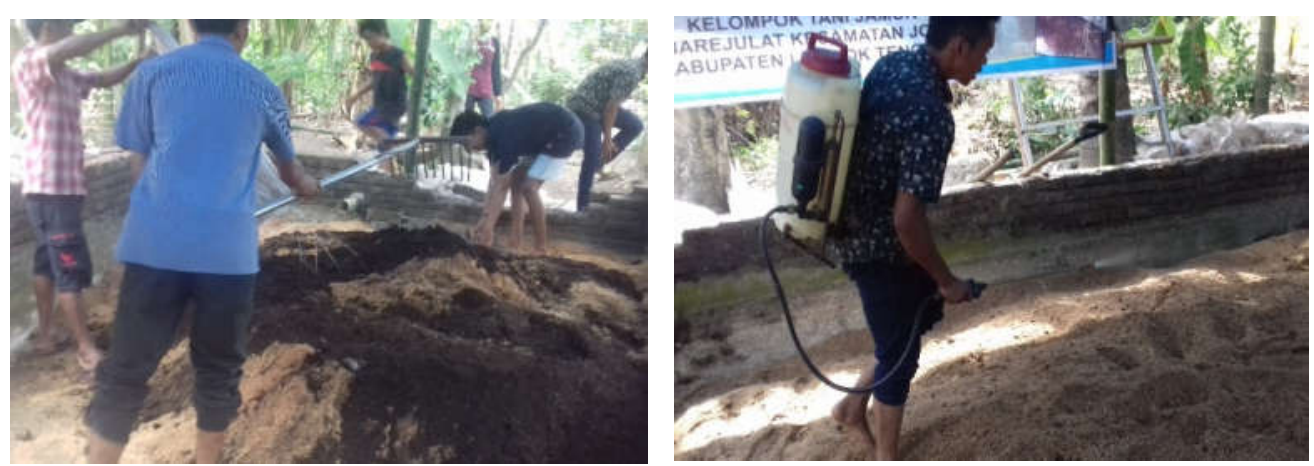

Gambar 3. Proses pencambuaran bahan dedak halus dan proses penyiraman EM4 dan larutan gula. (sumber: Doc. Pengambdian)

5. Penyusunan tumpukan

Bahan-bahan yang telah tercampur dengan rata, lalau disusun menjadi tumpukan. Penumpukan ini untuk mempermudah pengomposan dan pengontrolan bahan yang dikomposkan, penumpukan degan bentuk melingkar membentuk kerucut dengan keliling 1.5 mter dan tinggi 1, 16 meter. Seperti yang terlihat pada gambar berikut ini. 


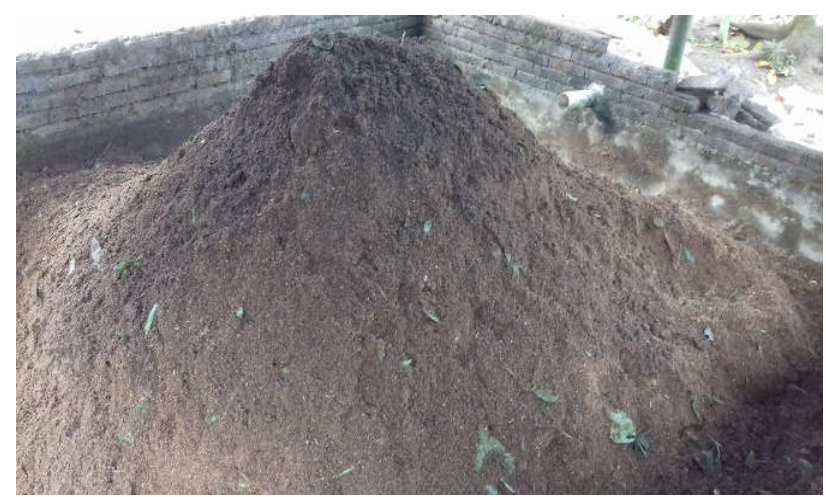

Gambar 4. Penumpukan Bahan-bahan yang telah dicampur untuk dikomposkan. (sumber: Doc. Pengambdian)

6. Fermentasi

Fermentasi dilakukan dengan cara menutup tumpukan yang telah dibuat dengan menggunakan terpal, dan dibiarakan selama 7 hari, penutupan dengan terpal bertujuan agar terjadi penaikan suhu sehingga didapatan suhu ideal untuk pertumbuhan mikroba, umumnya suhu berkisar $40^{\circ}-70^{\circ} \mathrm{C}$. Suhu awal pengomposan sama seperti suhu linkungan yakni $29 \mathrm{~s} / \mathrm{d} 30^{\circ} \mathrm{C}$. Pengontrolan suhu pada saat proses permentasi dilakukan 7 hari sekali hal ini dilakukan bertujuan untuk mengetahui peningkatan suhu pada bahan yang dikomposkan adapun hasil seperti yang terlihat pada Tabel 1 berikut ini

Tabel 1. Hasil pengukuran suhu pada proses permentasi pupuk organik

\begin{tabular}{lll}
\hline Minggu & Kondisi suhu & Keterangan \\
\hline 1 & $45^{\circ} \mathrm{C}$ & Adanya peningkatan aktivitas mikroba \\
2 & $55^{\circ} \mathrm{C}$ & Adanya peningkatan aktivitas mikroba \\
3 & $52^{\circ} \mathrm{C}$ & Adanya penurunan aktivitas mikroba \\
4 & $35^{\circ} \mathrm{C}$ & Adanya penurunan aktivitas mikroba \\
\hline
\end{tabular}

Tabel 1 menggambarkan bahwa aktivitas mikroba dalam proses pengomposan terjadi peningkatan dari suhu awal pada saat dimulai proses permentasi hal tersebut seperti yang ditunjukkan ada tabel di atas. Pada pertengahan minggu ke 5 suhu sudah mulai normal seperti pada suhu awal. Puncak peningkatan pada minggu ke 2 yakni mencapai $55^{\circ} \mathrm{C}$ dan mengalami penurunan pada minggu ke tingga sampai pada pertengahan minggu ke $5 \mathrm{suhu}$ sudah mulai normal seperti suhu awal pengomposan.

7. Pembalikan 
Pembalikan dilakukan 7 hari sekali. Bahan kompos diaduk-aduk kembali Dimaksudkan untuk membuang panas yang berlebihan, memasukkan udara segar ke dalam tumpukan bahan, meratakan proses pelapukan di setiap bagian tumpukan, meratakan pemberian air (60\% kadar air bahan), serta untuk menghaluskan bahan kompos yang masih berbentuk butiran kasar.

8. Penyiraman

Setelah beberapa hari melalui proses pengomposan, media kompos akan mengalami kehilangan air (dehidrasi) besar-besaran sebagai akibat panas. Oleh karena itu di butuhkan penambahan air. Penyiraman dilakukan terhadap bahan baku dan tumpukan yang terlalu kering (kelembapan kurang dari 50\%). Secara manual perlu tidaknya penyiraman dapat dilakukan dengan memeras segenggam bahan dari bagian dalam tumpukan. Apabila pada saat digenggam kemudian diperas tidak keluar air, maka tumpukan bahan baku harus ditambahkan air. Sedangkan jika sebelum diperas sudah keluar air, maka tumpukan terlalu basah oleh karena itu perlu dilakukan pembalikan.

9. Pendinginan

Setelah pengomposan berjalan \pm 33 hari, suhu tumpukan akan semakin menurun hingga mendekati suhu ruangan. Pada saat itu tumpukan telah lapuk, berwarna coklat tua atau kehitaman.

10. Pengemasan dan penyimpanan

Pengemasan pada dasarnya sebelumnya telah dilakukan oleh kelompok budidaya jamur tiram Lombok, sebelumnya mereka telah terbiasan mengemas jamur tiram dnegan menggunakan platik, akan tetapi menurut pengakuan anggota kelompok hasilnya belum menarik karena proses dilakukan dengan cara manual tidak menggunakan alat, selain itu untuk pelabelan mereka belum pernah karena mereka tidak bisa menggunakan komputer untuk mendisain label.

Kondisi tersebut mengharuskan tim PKM untuk melakukan pelatihan dan pendampingan dalam pembuatan label dan pengemasan menggunakan mesin pengemas. Dalam proses pelatihan dan pendampingan kelompok mitra sangat antusias hal tersebut terlihat dari semangat dan keaktifan mereka dalam mengikuti pelatihan dan pendapingan.

Pengomposan berakhir setelah kurang lebih 33 hari. Proses selanjutnya pengemasan dalam kantung sesuai dengan kebutuhan. Pengemasan dengan menggunakan 
plastik dengan ukuran $5 \mathrm{~kg}$ dan $10 \mathrm{~kg}$. Hal tersebut bertujuan agar mempermudah pemasaran.

\section{Respon Pelaksanaan Kegiatan}

Kegiatan PKM yang dilaksanakan di Kelompok budidaya jamur tiram Lombok dusun Bat Rurung Desa Bare Julat merupakan kegiatan yang petama kali dilakukan. Terbukti dari keaktifan peserta dalam mengikuti semua rangkaian kegiatan yang telah dirancang. Selain keaktifan mereka juga menunjukkan respon yang sangat puas setelah mendapatkan pelatihan dan pendampingan. Pemantauan kemajuan pengolahan limbah baglog jamur secara berkala terus dilakukan oleh Tim untuk melihat kualitas produk yang dihasilkan. Hasil dari kegiatan ini telah mampu memberikan peluang dan memberikan nilai tambah bagi para anggota, baik dari segi pengetahuan dan keterampilan, maupun dalam hal peningkatan perekonomian kelompok. Hal ini diuangkap melalui pengakuan ketua kelompok dan para anggotanya. Dengan demikian, kegiatan pelatihan ini telah memberi dampak yang positif bagi kemajuan dan peningkatan pendapatan dari kelompok budidaya jamur tiram.

\section{KESIMPULAN}

Berdasarkan hasil pelaksanaan kegiatan, maka dapat disimpulkan bahwa: (1) kelompok budidaya jamur tiram lombok yang dibina telah memahami prosedur atau cara pembuatan pupuk Kompos organik dari limbah media baglog jamur tiram, 2) Kelompok budidaya jamur tiram lombok telah memiliki pengetahuan dan keterampilan yang lebih baik tentang cara pengemasan dan pelabelan produk, dan 3) produk pupuk yang dihasilan dapat dikomersilkan dan berdampak pada bertambahnya pendapatan kelompok budidaya jamur tiram lombok.

\section{UCAPAN TERIMAKSIH}

Atas terselengaranya kegiatan pemberdayaan kelompok budidaya jamur dalam pemanfaatan limbah baglog jamur menjadi pupuk organik, kami dari tim PKM IKIP Mataram mengucapkan banyak-banyak terimakasih kepada Kmenristekdikti yang telah membiayai sampai terselesaiakannya PKM yang dilakukan di Desa Bare Julat, trimaksih kepada bapak kepala desa Bare Julat yang telah memberikan izin dan pasilitas selama kegiatan pelatihan, dan ucapan trimaksih kepada masyarakat kelompok budidaya jamur tiram lombok yang telah bersedia sebagai mitra dalam kegaitan PKM. 


\section{DAFTAR PUSTAKA}

Ardianingsih M., Aulia N.H., Soraya D., W.G.G.A., Kartika., Nihaya L., Pitriani P., 2018. Laporan Paraktik Kerja Lapangan Bidang Gizi Masyarakat desa Bare Julat Kecamatan Jonggat Kabupaten Lombok Tengah. https://www.scribd.com/document/376440307/Laporan-PKLBGM-Desa.

Alex S., 2013. Sukses Mengolah Sampah Organik menjadi pupuk organic. Yogyakarta; Pustaka Baru Press.

Hunaepi, Dharmawibawa D.I., Samsuri T. 2014. Pemanfaatan Limbah Media Jamur Sebagai Pupuk Organik (IbM Kelompok Tani). Jurnal Ilmiah IKIP Mataram. 1(2).

Rahmah L.N., Styaningtyas A.N., Hidayat N., 2016. Compost characteristic from oyster mushrooms baglog's waste (study of em4 and goat manure concentration. Jurnal industria $4(1), 1-9$.

Sulaiman D, 2011. Efek kompos limbah baglog jamur tiram putih terhadap sifat fisik tanah serta pertumbuhan bibit markisa kuning. Bogor : intitut pertanian bagor diakses melalui repository.ipb.ac.id/jspui/bitstream/123456789/53343/1/A11dsu.pdf

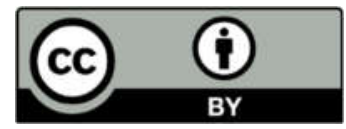

2018 Oleh authors. Lisensi Jurnal Solma, LPPM-UHAMKA, Jakarta. Artikel ini bersifat open access yang didistribusikan di bawah syarat dan ketentuan Creative Commons Attribution (CC BY) license (http://creativecommons.org/licenses/by/4.0/). 